\title{
Specificity and Sensitivity of Screening for Anti-HLA Antibodies in Kidney Allograft Dysfunction
}

\author{
H. Viana, F. Nolasco, M.C. Santos, F. Carvalho, M.J. Galvão, A.R. Santos, J. Bordalo, and \\ J.R. dos Santos
}

\begin{abstract}
Background. Prospective testing for posttransplant circulating anti-HLA antibodies seems to be a critical noninvasive tool, but confirmatory data are lacking.

Materials and Methods. Over the last 3 years, peritubular capillary (PTC) C4d deposition was prospectively sought by an immunofluorescence technique applied to frozen tissue in biopsies obtained for allograft dysfunction. Screening for circulating anti-HLA class I/II alloantibodies (AlloAb) by the flow cytometric test was performed simultaneously.

Results. We evaluated 132 sets of biopsies and simultaneous serum samples. PTC C4d deposition was demonstrated in $15.9 \%$ (21/132) of biopsies. Circulating anti-HLA I/II AlloAb were detected in 25\% (33/132) of serum samples. Employing receiver-operator characteristic (ROC) curves for all C4d-positive biopsies, screening for AlloAb showed a global specificity of $82 \%$ and sensitivity of $61.9 \%$. When this analysis was restricted to biopsies obtained in the first month posttransplantation, the sensitivity increased to $81.8 \%$, but the specificity decreased to $76.9 \%$. After the first month posttransplantation, we observed sensitivity of $40.0 \%$ and a specificity of $86.4 \%$. In the first month posttransplantation, all patients with a diagnosis of acute antibody-mediated rejection displayed circulating anti-HLA class I/II, but not always at the same time as the C4d-positive biopsy.

Conclusions. In the first month posttransplantation, prospective monitoring of antiHLA antibodies may be useful. The high sensitivity allows the identification of patients at risk, affording an earlier diagnosis of antibody-mediated rejection. After the first month, the test can be used to evaluate allograft dysfunction episodes, since positivity is highly suggestive of an antibody-mediated process.
\end{abstract}

$\mathbf{P}$ RESENTLY, anti-HLA antibodies are recognized as important mediators of acute and chronic rejection, differing in pathogenesis from T-cell-mediated rejection. Alloantibodies (AlloAb) preferentially attach to peritubular and glomerular capillaries, in contrast to $\mathrm{T}$ cells, which typically infiltrate tubules and arterial endothelium. The important role of these anti-HLA AlloAb in mediating rejection had been emphasized first by Terasaki. ${ }^{1}$ The antibodies found in the peripheral circulation were not necessarily donor-specific, and their association with failure was consistent with a causality hypothesis. ${ }^{2}$ Several studies observed that patients who had rejected transplants displayed anti-HLA antibodies more frequently than those with functioning grafts. Hence it was concluded that screening for HLA antibodies posttransplantation could be an important tool in patient follow-up. ${ }^{3,4}$ Deposition of complement fragment $\mathrm{C} 4 \mathrm{~d}$ in peritubular capillaries (PTC) is a marker of alloantibody-dependent graft injury. Currently, several questions need to be answered regarding the monitoring of circulating HLA antibodies. ${ }^{5}$ What is the more useful method? What is the optimal timing and frequency of monitoring? The purpose of our study was to determine the sensitivity and specificity of screening for circulating

From the Hospital Curry Cabral, Servico de Nefrologia, Lisboa, Portugal.

Address reprint requests to Helena Viana, Serviço de Nefrologia do Hospital Curry Cabral, Rua da Beneficência 8, 1600 Lisboa, Portugal. E-mail: Viana.helena@gmail.com

0041-1345/09/\$-see front matter doi:10.1016/j.transproceed.2009.02.008 
anti-HLA antibodies compared to the present gold standard test (C4d deposition in renal tissue).

\section{MATERIALS AND METHODS}

Over the last 3 years, we prospectively evaluated C4d deposition by an immunofluorescence technique applied to frozen allograft biopsy tissue (monoclonal antibody, Quidel) which had been obtained due to renal dysfunction or delayed graft function. A serum sample was obtained at the time of the biopsy to detect the presence of circulating anti-HLA class I/II AlloAb by the flow cytometric assay (FlowPRA screening test, Lambda one). The clinical parameters were registered at biopsy time. Data analysis was performed using the MedCalc software 9.0.1.1. Descriptive data were expressed as mean values \pm standard deviations. Fisher test and independent sample Student $t$ test were used for comparisons of groups. Receiver-operator characteristic (ROC) curves were used to calculate the sensitivity and specificity of the test (serum anti-HLA antibodies) for the disease (PTC C4d in renal tissue). Antibody-mediated rejection was diagnosed according to the 2007 Banff classification. ${ }^{6} P<.05$ was considered to be significant.

\section{RESULTS}

We evaluated 132 biopsies and simultaneous serum samples in 92 patients (Table 1). PTC C4d deposition was demonstrated in $15.9 \%(21 / 132)$ of biopsies. We observed no significant difference between the incidence of C4d in PTC before or after the first month posttransplantation $(17.5 \%$ vs $15.5 \%$ ). Anti-HLA I/II AlloAb were detected in $25 \%$ (33/132) of serum samples at $31.6 \pm 54.6$ months posttransplantation. Among the positive serum samples observed in the first month after transplantation, 90.4\% (19/21) were obtained from patients with panel-reactive antibodies (PRA) $\geq 75 \%$ before transplantation. All patients with acute antibody-mediated rejection (AMR; $n=11$ ) in the first month posttransplantation showed a positive result for circulating anti-HLA class I/II AlloAb, but not always in the simultaneous sample obtained concomittant with the index C4d-positive biopsy. Employing ROC curves (Table 2), we observed that screening for AlloAb showed a global specificity of $82 \%$ and a sensitivity of $61.9 \%$. We found 8 false negatives: 6 biopsies (obtained at $7.8 \pm 2.2$ years posttransplantation) had additional evidence of chronic antibodymediated rejection (CMR) and 2 biopsies obtained during treatment of AMR $(0.34 \pm 0.15$ years $)$. When the analysis was restricted to biopsies obtained in the first month posttransplantation, the sensitivity increased to $81.8 \%$, with a specificity of $76.9 \%$. After the first month posttransplantation, the sensitivity was $40.0 \%$ and the specificity was $86.4 \%$.

\section{DISCUSSION}

\section{First Month Posttransplantation}

In August 2007, the transplant allocation scheme changed in our country, with extra points awarded to sensitized patients. These allocations changes explained the high number of highly sensitized patients transplanted in the study period. We observed a high sensitivity for the method in the first month after transplantation. Almost all the patients with a positive screening test for anti-HLA antibodies in the first month were highly presensitized (PRA $\geq 75 \%$ ) before transplantation, supporting the conclusion that these antibodies were probably preformed and not de novo generated. The absence of an absolute correspondence between the existence of circulating antibodies and C4d deposition may be explained by the different dynamics of timing between anti-HLA antibody detection, complement activation, and renal tissue damage, which are still not well understood.

A novel interesting approach could be the evaluation of sequential antibody titers in addition to $\mathrm{C} 4 \mathrm{~d}$ deposition in protocol biopsies. This type of study could elucidate the dynamics and timing of antibody-mediated rejection to clarify whether antibody titers could dictate the appropriate timing of a renal biopsy, and their usefulness to monitor renal damage and therapeutic responses.

\section{After 1 Month Posttransplantation}

The high specificity of the test signified that a positive result was associated with an episode of allograft dysfunction mediated by antibody and therefore useful for diagnosis. The lower sensitivity in antibody-mediated processes after the first month can be explained by 2 hypotheses: anti-HLA antibodies are absorbed by the graft and not detected in serum and other non-anti-HLA antibodies may be involved. For example, other antibodies such as those against endothelial cells observed in renal transplant recipients have been associated with graft loss. The impaired allograft

Table 1. Patient Characteristics

\begin{tabular}{|c|c|c|c|c|}
\hline & $\begin{array}{c}\text { Total } \\
(\mathrm{N}=132)\end{array}$ & $\begin{array}{c}\text { Anti-HLA Antibody } \\
\text { Positive }(n=33 ; 25 \%)\end{array}$ & $\begin{array}{l}\text { Anti-HLA Antibody } \\
\text { Negative ( } \mathrm{n}=99 ; 75 \%)\end{array}$ & $P$ \\
\hline Age (y) & $48.0 \pm 12.6$ & $46.5 \pm 11.7$ & $48.5 \pm 12.9$ & .434 \\
\hline Gender & $63 \mathrm{~F} ; 69 \mathrm{M}$ & $19 \mathrm{~F} ; 14 \mathrm{M}$ & $44 \mathrm{~F} ; 55 \mathrm{M}$ & .2684 \\
\hline Race & $118 \mathrm{C} ; 14 \mathrm{~A}$ & $27 \mathrm{C} ; 6 \mathrm{~A}$ & $91 \mathrm{C} ; 8 \mathrm{~A}$ & .1917 \\
\hline Creatinine $(\mathrm{mg} / \mathrm{dL})$ & $3.3 \pm 2.1$ & $3.5 \pm 2.7$ & $3.2 \pm 1.9$ & .471 \\
\hline Time posttransplantation (mos) & $39.3 \pm 55.5$ & $31.6 \pm 54.6$ & $41.8 \pm 55.8$ & .366 \\
\hline C4d positive & $21(15.9 \%)$ & 13 & 8 & .0001 \\
\hline Previous transplantation & $25(18.9 \%)$ & 12 & 13 & .0071 \\
\hline$P R A \geq 75 \%$ & $33(25 \%)$ & 18 & 15 & $<.0001$ \\
\hline
\end{tabular}

F, female; M, male; C, Caucasian; A, African; PRA, panel-reactive antibodies. 
Table 2. Sensitivity and Specificity of the Test

\begin{tabular}{lccccc}
\hline & Sensitivity (\%) & $95 \% \mathrm{Cl}$ & Specificity (\%) & $95 \% \mathrm{Cl}$ & Area Under Curve \\
\hline Total & 61.90 & $38.5-81.8$ & 81.98 & $73.6-88.6$ & .719 \\
$\leq 1$ month posttransplantation & 81.82 & $48.2-97.2$ & 76.92 & $63.2-87.5$ & .794 \\
$>1$ month posttransplantation & 40.0 & $12.4-73.6$ & 86.44 & $75.0-93.9$ & .632 \\
\hline
\end{tabular}

$\mathrm{Cl}$, confidence interval.

survival of patients with MICA antibody ${ }^{7}$ and the finding of MICA antibodies in eluates of kidney transplants suggest that they can be involved in the pathogenesis of kidney allograft rejection. ${ }^{8}$

In conclusion, in the first month after transplantation, the prospective sequential monitoring of anti-HLA antibodies using a screening technique is useful. The high sensitivity allows the identification of at-risk patients and affords earlier procedures for diagnosis of antibody-mediated rejection including appropriate timing for identification of specific anti-donor antibodies using other more expensive solid phase assays (Luminex). After the first month, the test can be used to evaluate an allograft dysfunction episode, since positivity highly suggests an antibodymediated process.

\section{REFERENCES}

1. Terasaki PI: Humoral theory of transplantation. Am J Transplant 3:665, 2003
2. Mizutani K, Terasaki P, Rosen A, et al: Serial ten-year follow-up of HLA and MICA antibody production prior to kidney graft failure. Am J Transplant 5:2265, 2005

3. Terasaki PI, Osawa M, Castro R: Four-year follow-up of a prospective trial of HLA and MICA antibodies on kidney graft survival. Am J Transplant 7:408, 2007

4. Hourmant M, Cesbron-Gautier A, Terasaki PI, et al: Frequency and clinical implication of development of donor-specific and non-donor-specific HLA antibodies after kidney transplantation. J Am Soc Nephrol 16:2804, 2005

5. Cai J, Terasaki PI: Post-transplantation antibody monitoring and HLA epitope identification. Curr Opin Immunol 20:1, 2008

6. Solez K, Colvin RB, Racusen LC, et al: Banff 07 classification of renal allograft pathology: updates and future directions. Am J Transplant 8:753, 2008

7. Zou Y, Stastny P, Susal C, et al: Antibodies against MICA antigens and kidney transplant rejection. N Engl J Med 13:1293, 2007

8. Zou Y, Heinemann F, Grosse-Wilde H, et al: Detection of anti-MICA antibodies awaiting kidney transplantation, during the post-transplant course, and in eluates from rejected kidney allograft by Luminex flow cytometry. Hum Immun 67:230, 2006 